\title{
Strategies for Promoting Coordinated Development of Urban and Rural Regional Economic Circulation in China
}

\author{
Su Teng \\ Guangxi Zhuang Autonomous Region Development and Reform Commission, Guangxi Nanning, 530022
}

Keywords: urban regional economy; circulation industry; coordinated development

\begin{abstract}
At present, China has become the second largest economic complex in the world. However, in a long period of time, the economic development of China depends to a large extent on the market of some developed countries in the world, which leads to the unbalanced trade structure, frequent trade frictions, and serious impact on the production of related industries. The occurrence of face problems and the outbreak of the world economic crisis will have serious adverse effects on the economic development of our country. In this case, our government resolutely adopts the policy of expanding domestic demand. In the process of expanding domestic demand, it is found that the imbalance between urban and rural consumption and the flow industry is rather serious. Therefore, it is of great practical significance to explore the strategy of promoting the coordinated development of urban and rural regional economic circulation in China. Firstly, this paper analyzes the current situation of the development of the regional economic circulation industry in urban and rural areas in China, and then points out its existing problems, and finally puts forward some countermeasures and suggestions.
\end{abstract}

\section{The Current Situation of Regional Economic Circulation in Urban and Rural Areas in China}

China is a dual economic structure. Although China has accelerated the speed of urbanization in recent years, the rural population of China still accounts for the majority, and the rural economy is still far behind the urban economy. From the perspective of economic development, the integration of urban and rural areas is the customer requirement of increasing integration of rural economy and urban economy in modern economy. With the continuous development of the urban and rural circulation system in China, the circulation industry has become an important leading industry for the economic development of our country. It plays an important role in the process of promoting the integration of urban and rural areas in China, and the multi angles and multi aspects between urban and rural areas are increasingly relying on the modern circulation, such as the model of mobile organization and management canal and so on.

Since the reform of the seventy and eighty dynasties in the last century, there have been many changes in the circulation system between the rural and urban areas in China, such as the diversification of the circulation channels and the market model. Due to the impact of the global economic crisis, China's export has been declining for ten years, coupled with grain harvest in China in the recent years, which makes our agricultural products oversupply. On the other hand, many industries are in a situation of overcapacity. It is necessary to try kinds of means to expand domestic demand and strengthen urban and rural overall planning and interaction to promote the circulation and coordinated development between urban and rural areas.

\section{Problems in the Circulation System of Urban and Rural Areas}

\subsection{Aspects of institutional obstacles}

The main reason for the system obstacle in the urban and rural circulation system is that there are many institutional obstacles between the big, middle, small cities and rural areas in our country, which has a serious hindrance to the development of the integrated urban and rural areas in China. It 
is mainly reflected in the system of "dining in the kitchen". Although many areas have set up the thinking form of the common development of urban and rural areas, the coordination is very bad, and the focus is that the efficiency of circulation is not high, the urban market is still not good for the development of the agricultural products market, and the agricultural products can not meet the city market need. It is necessary to make it difficult for farmers to increase their income.

\subsection{On the shortage of income tax policy of agricultural products}

In the formulation of the entry deduction system of agricultural and sideline products, the value added tax paid to the state in the business license is paid by the general tax person to purchase the agricultural and sideline products which do not have to pay taxes to the agricultural individual producers in a small amount of cash, and allow it to set up the "purchase invoices" provided by the tax authorities to deduct input tax according to the 0.13 deduction rate. This policy can reduce the burden of the acquisition of agricultural products, thus accelerating the development of rural economy and the flow of agricultural and sideline products. However, in the actual implementation process, the tax authorities will also use some specific management measures, such as the tax holders, with their own identity cards, or by marketing one's own products to prove the authenticity of the invoice, which makes the purchase of agricultural products acquisition of legitimate purchase invoice become more difficult.

\subsection{Some leading markets in China are not taking the lead and the role of radiation obviously at present.}

So far, there are 600 cities in our country. Although the integration of urban and rural areas has developed rapidly, the famous large and medium-sized enterprises in urban and rural circulation are few in general. The structure is more unreasonable and the competitiveness is not strong. In addition to the small size of large major market, small organization, small influence, small circulation enterprises and low degree of organization, the larger trading market of professional raw materials and products is not much.

\subsection{Infrastructure construction remains to be improved.}

The traffic and communication network system of the city circle is not perfect. The traffic facilities between the large, middle and small cities and the rural areas are not perfect. Many highways are still in the unfinished state, and many cities have not built the function of highway network. The high highway between cities has not formed a traffic network. Although the central city and the cities have achieved high speed, the high-speed connectivity also needs to bypass the big cities. Rural roads have no form traffic network system, and there are too many toll stations, resulting in increased traffic costs.

\section{Basic Principles for the Integration of Urban and Rural Areas}

\subsection{Adhere to the basic principles of reform ahead of schedule and plan ahead}

The so-called urban and rural integration means breaking the old forms and systems of the rural circulation, daring to be bold and innovative, and insisting on the "three new" concept (new thinking, new system and new format) to promote the development of the circulation industry in urban and rural areas in China. The integration of urban and rural integration should be based on the planning of each city. The first is to study and formulate the strategic planning of urban and rural circulation development, and take practical plan and measures to realize the strategic planning of urban and rural integration.

\subsection{Adhere to the basic principles of government guidance and market regulation.}

To promote the integration of urban and rural areas, we must deal with the relationship between the market and the government. The main responsibility of the government is to promote the integration of urban and rural areas by scientific guidance and planning, but not directly or indirectly to participate in the integration of urban and rural circulation, and to create a good 
environment for the integration of urban and rural areas. Accelerating the integration of urban and rural areas is usually the market .Therefore, it is necessary to strengthen the free regulation role of the market. With the role of market regulation, the urban and rural resources can be optimized and combined to flow freely through the urban market.

\subsection{Adhere to the principle of coordination}

It mainly includes two aspects: on the one hand, it refers to the coordination of the mutual development between cities, urban and rural areas and all walks of life, on the other hand, to coordinate the exchange of information on infrastructure and circulation of information between cities and rural areas. We should strengthen the support of large commercial enterprises, city commercial centers and docking of agricultural products and large supermarkets.

\section{Countermeasures and Suggestions to Promote the Integration of Urban and Rural Areas}

\subsection{Support a batch of large and medium-sized circulation enterprises}

From some of the famous multinational retail enterprises in the world and the successful wholesalers who have been successful in operation, we can make our country produce a lot of large and medium-sized enterprises with strong competitiveness, and form a unified commercial sign and commodity purchase, distribution and service standards to establish the of multi-layer business network support between the large and medium-sized circulation enterprises in the countryside and the cities, making local business enterprises bigger and stronger. Encourage and guide a number of conditional circulation enterprises to explore the form of joint development between agricultural products and large supermarkets in cities.

\subsection{Develop special product trading market cluster}

Give full play to the advantages of urban and rural areas, such as transportation advantages and unique advantages of geographical location. According to the requirements of "scientific layout, improving function and expanding radiation", it is important to support the expansion of a part of the better commodity trading market group to make it develop rapidly and make it an important circulation area of agricultural and sideline products.

\subsection{Develop agricultural products base}

We should give priority to the development of a certain scale and well-known agricultural and sideline products production base. It has become the inevitable trend of the rural economy in many areas of our country to take the mobile enterprises to bring farmers in the future. It plays an important role in accelerating the development and improvement of urban and rural integration in the process of economic development of urban and rural areas. To strengthen the docking of agricultural and sideline products with the large and medium-sized supermarkets in the city, the advantages of the rural and urban circulation enterprises have been fully brought into play, thus achieving the goal of win-win. This development form should be taken as a focal point for realizing the integration of urban and rural areas and promoting the coordinated development of urban and rural economy. As a key enterprise and core enterprise which can absorb a large amount of agricultural and sideline products, the state and government at all levels should give high attention and increase support to establish a base of agricultural and sideline production with certain influence in the countryside.

\subsection{Strengthen the establishment of modern logistics park}

Strengthen the development of logistics enterprises, especially for the agricultural products logistics and daily life logistics enterprises to give priority to support, the other party focus on the establishment of public logistics area planned by the government. At the same time, we should strengthen the development of retail enterprises to concentrate and unified distribution of goods in the logistics distribution, and optimize the various related logistics resources. A large number of large and medium-sized logistics and warehousing enterprises have been developed, and the 
modernization level of their enterprises has been continuously upgraded so as to enhance the efficiency of commodity circulation.

\subsection{Promote the Internet trading platform}

Vigorously develop the main body of circulation to participate in e-commerce platform for transactions. Agricultural products trading mode develop through the e-commerce platform to establish an Internet trading platform.

It is also necessary to update and enrich the relevant information on the agricultural product platform, and the conditional e-commerce platform can also recruit relevant agricultural products experts to analyze and comment on related information, and also explain the related agricultural marketing knowledge on the platform, provide guidance to the agricultural product e-commerce platform for the network marketing. It contributes to the development and prosperity of the product platform.

\section{References}

[1] He Yongquan. Restricting factors and supporting system construction of urban and rural commercial circulation system in China [J], reform and outline, 2017, (07): 123-126.

[2] Lu Yan Na. Construction value and strategic thinking of urban and rural two-way business circulation system [J]. Business economics, 2017 (01): 17-18.

[3] Liu Ying. Discussion on the construction of modern commercial circulation system in Hunan's urban and rural areas [J]. Foreign trade, 2015 (10): 84-85+146.

[4] Yuan Shu. Necessity and mode of rural commercial circulation system construction [J]. business economics research. 2016 (16): 152-154. 